\title{
SOBRE O COMPORTAMENTO SEMÂNTICO DE "QUALQUER"
}

Márcio Renato Guimarães*

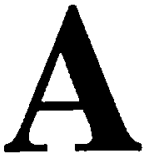

o se adaptar para o "quantificador"1 QUALQUER, do português, a análise feita por Vendler (1967) para o ANY do inglês, uma ressalva deve ser feita de antemão. O significado de ANY cobre mais coisas que o de QUALQUER:

(1)

a. Take any one.

b. Pegue qualquer uma.

(2)

a. Did you take any?

b. Você pegou alguma?

(3)

a. I don't take any.

b. Eu não peguei nenhuma.

* Mestrando em Letras da Universidade Federal do Paraná.

1 Na falta de termo methor, usa-se quantificador, entre aspas, para se referir a palavras, nas linguas naturais, que correspondem mais ou menos aos quantificadores da lógica. Apesar das diferenças, a denominação é preferivel àquela dada pela gramática tradicional. 
Autores posteriores, trabalhando com o inglês, reconheceram, segundo Kadmon e Landman (1993), as diferenças de uso de ANY, distinguindo, por um lado, um ANY "sensivel à polaridade negativa" (POLARITY SENSITIVE - PS), como em (3) a; e, por outro lado, um ANY que tem uma interpretação de "livre escolha" (FREE CHOICE-FC), como em (1) a e (2) a. O primeiro corresponde, basicamente, ao nosso NENHUM(A), e não nos interessa aqui. O segundo corresponde ao nosso QUALQUER e, em alguns contextos, a ALGUM(A).

A noção de livre escolha (free choice) foi introduzida por Vendler (1967) e é tida como essencial nas análises posteriores de ANY, a ponto de servir de parâmetro para a distinção dos dois usos. Vendler (1967) também estabeleceu duas outras noções: a de verificação e a de incompletude. No presente estudo, faremos uso das mesmas três noçōes, tentando estabelecer uma relação entre elas. Tomaremos a noção de verificação como básica, o que se tentará justificar no item 1. Nos itens seguintes demonstraremos como esta noção implica as outras duas. A noção de livre escolha sofrerá um pequeno alargamento com a introdução da noção de escolha aleatória, necessária para a interpretação dos usos de QUALQUER. Para a análise da última noção, far-se-á uso do conceito de exceções legítimas, segundo Kadmon e Landman (1993).

\section{Sobre verificações e modos}

QUALQUER tem uma interpretação básica em comum com os dois outros "quantificadores universais" do português -TODO e CADA- que é a predicação sobre a totalidade dos elementos de um conjunto, expressa pelo quantificador universal da lógica. Isso significa que as três frases de (4) a (6) têm uma interpretação em comum, a nível lógico, expressa em (7):

(4) Todo homem é mortal.

(5) Cada homem é mortal.

(6) Qualquer homem é mortal.

(7) $\forall(\mathrm{Hx} \rightarrow \mathrm{Mx})$ em que: $\mathrm{H}:$ "ser homem"

M: "ser mortal"

(4) e (6) - para tomarmos apenas a oposição entre TODO e QUALQUER, que é o que nos interessa - não têm exatamente o mesmo significado, ou melhor dizendo, o mesmo alcance. Em (4) é a frase que melhor representa o que está expresso em (7), sem introduzir noções adicionais, como nas seguintes. Em (6) temos, pelo menos, o acréscimo de uma noção básica, a de verificação, derivada 
de uma implicação inerente ao que é significado em (4)/(7). A implicação é que se é verdadeiro para todos, será verdadeiro para cada um dos elementos, individualmente, portanto, isso pode ser verificado com a escolha - aleatória ou não, como veremos - de um único desses elementos. QUALQUER, mais do que fazer uma afirmação, deixa implícita uma garantia, uma vez que oferece a possibilidade de verificação. No item 3 veremos até onde vai o escopo dessa garantia.

Poder-se-ia obstar que a mesma verificação também poderia ser construída com TODO e CADA, além de QUALQUER, como se observa de (8) a (10). De fato, isso é verdade. Porém com QUALQUER, a operação de verificação é essencial c está sempre presente. Com CADA e TODO a verificação aparece apenas em alguns contextos sintáticos específicos.

a. Qualquer teoria que se bascia nessa hipótese é falsa.

b. Qualquer teoria que se baseie nessa hipótese será falsa.

a. Toda teoria que se bascia nessa hipótese é falsa.

b. Toda teoria que se baseie nessa hipótese será falsa.

a. Cada teoria que se baseia nessa hipótese é falsa.

b.? Cada teoria que se baseic nessa hipótese será falsa.

Observe-se que todas as sentenças no subjuntivo referem-se a conjuntos virtuais. No indicativo, isso só acontece com QUALQUER (8) a. Aliás, o fato de TODO, em (9) a., operar com um conjunto pré-construído de elementos pōe em cheque a análise de Mira Mateus (1989), ${ }^{2}$ que deu como descartada essa hipótese.

Essa característica de QUALQUER de não depender do modo verbal para operar conjuntos virtuais talvez implique um status de operador modal. Isso merece uma análise mais aprofundada, o que depende, na sua maior parte, de uma análise sobre as relaçōes modais em geral no português. com TODO O.

2 Ver a pequena e apressada análise, na p. 68. Além disso, os autores confundem TODO 


\section{Liberdade de escolha e escolha aleatória}

Como vimos no item a. anterior, a verificação proposta por QUALQUER implica uma escolha. Lembre-se, também, de que existe uma garantia, que se estende a todos os membros do conjunto quantificado. Portanto, não importa qual seja escolhido e, devido a isso, pode-se garantir total liberdade ao interlocutor para que ele faça a escolha.

Vimos que essa liberdade de escolha tem sido encarada como essencial para a interpretação do FCANY do inglês. Para QUALQUER, porém, só essa noção é insuficiente. Isso se dá porque QUALQUER expressa mais do que a liberdade de escolha, expressa também o caráter aleatório que a escolha pode ter. Para ver como isso se dá, vamos retomar um exemplo de Vendler (1967). Suponhamos que eu tenho nas mãos um cesto de maçãs e digo ao meu interlocutor:

(11) Pegue qualquer uma.

Embora eu esteja restringindo a escolha dele a uma quantidade pré-estabelecida, eu estou dando a ele a liberdade de escolher qual pegar. Meu interlocutor pode usar o critério que quiser. Ele pode pegar a maior, a menor, a mais verde, a mais madura, e assim por diante. E ele pode, também, fechar os olhos, estender a mão e pegar ao acaso, e depois dizer:

(12) Peguei qualquer uma.

A sentença (11) é ambígua, podendo significar tanto “eu estou dando a você a liberdade de escolher a que quiser" como "não se dê ao trabalho de escolher, pegue aleatoriamente", ou ainda, admitindo as duas possibilidades ao mesmo tempo. Mas (12) nunca será ambígua, sempre dando a entender que a escolha foi aleatória.

Se, por um lado, em qualquer das possibilidades de (11) a liberdade de escolha continua valendo, por outro lado, não se pode dizer que uma escolha é aleatória enquanto ela não é realizada. Deduz-se que há uma distinção bem clara entre a liberdade de escolha e a escolha aleatória, e a fronteira entre as duas é a mesma que separa o momento antes do momento depois da escolha.

Esta distinção se torna patente quando se compara o uso de QUALQUER com o de ANY. É ela que explica o fato de ANY, em (2) a., ser interpretado como ALGUMA, que corresponde ao quantificador existencial da lógica. Isso daria, para (2) - esquecendo-se do fato de que se trata de uma pergunta, pelo menos por ora, a seguinte forma lógica: 


$$
\begin{aligned}
\exists x(P v x) \text { em que: } & \text { P: "pegar” } \\
& \text { v: "você” }
\end{aligned}
$$

Note-se que a pergunta feita em (2) pode ser encarada como um teste, uma verificação. Os quantificadores $\mathrm{FC}$ oferecem, como veremos no próximo capítulo, a possibilidade de verificação. Em (2) a. o que se pergunta é se a escolha (proposta em (1) a., por exemplo) foi feita ou não.

Agora, observe-se o que acontece se nós traduzirmos ANY $\mathrm{em}(2)$ a. por QUALQUER (uma):

(14) Você pegou qualquer uma?

Como, ao contrário de ANY, QUALQUER permite a interpretação de escolha aleatória, o que se está testando em (14), mas não em (2) a., é se a escolha foi ou não aleatória. $O$ fato de ANY não trabalhar com essa noção é que permite a interpretação de (2) a. como simples verificação de escolha.

A simples verificação de escolha (em (2) a. e b.) recai sobre um elemento: esse é o número de elementos (neste caso) a que foi restrita a possibilidade de escolha. Observe-se que é uma pergunta que pede uma resposta do tipo sim/não, que correspondem aos dois valores de verdade que (6) pode ter.

Interessante notar como a posposição de QUALQUER leva inevitavelmente à interpretação como escolha aleatória:

(15) Pegue uma qualquer.

(16) Peguei uma qualquer.

(16) Significa, como era de se esperar, o mesmo que (12). Já (15) não é mais ambigua, como (11). Parece, todavia, que QUALQUER, aqui, não é mais um quantificador, mas antes um adjetivo:

(17) Peguei uma qualquer

$$
\text { verde }
$$

grande

Vê-se, assim, como é fundamental, para a interpretação dos usos de QUALQUER, a introdução da noção de escolha aleatória junto com a de liberdade de escolha. Por outro lado, viu-se também como a introdução dessa noção explica a aparente disparidade com o ANY do inglês, nos contextos em que este é traduzido como ALGUM(A). 


\section{Incompletude e exceções legítimas}

No item 1, vimos que QUALQUER pode ser interpretado no sentido de uma garantia para a verdade da quantificação universal inerente ao seu significado. Neste item, introduziremos uma noção que está em aparente contradição com essa garantia: a de incompletude do escopo de QUALQUER.

Essa incompletude se deve, em primeiro lugar, como observam Kadmon e Landman (1993), à existência de exceções legítimas, que escapam da garantia proposta, sem lhe comprometer seriamente a verdade, num sentido mais geral. Considere-se (18):

(18) Qualquer gato caça ratos.

Alguns casos escapam da garantia expressa em (18). Um gato doente, um fillhote de três semanas de idade, ou mesmo um gato morto não caçam ratos. Mas isso não compromete a garantia de (18), nem lhe tira a sua larga possibilidade de verificação. Infelizmente, não se pode dizer que isso se aplique a todos os casos de uso de QUALQUER, como o de (6), por exemplo.

Mas, mesmo não se considerando as exceções legítimas, a incompletude do escopo de QUALQUER se mantím. Isto se dá porque QUALQUER nunca exaure todas as possibilidades. Nenhuma verilicação o faz, a não ser em teoria. É como uma Reductio ad Absurdum, algo como "se você verilicar todos os gatos do mundo, um por um, verá que eles caçam ratos".

Podemos, se assim o preferirmos, como diz Vendler (1967), rotular a verilicação introduzida por QUALQUER como "verificação incompleta". Podemos dizer também, e não será mentira, que QUALQUER opera com generalizações, ou que a verificação, e também a liberdade de escolha, inerentes ao seu signilicado, têm um grande valor persuasivo, e poderíamos chamá-lo de "operador retórico" ou algo que o valha.

Note-se, a respeito da cscolha, que o que se falou sobre incompletude se mantém da mesına maneira. Retornemos às maçãs de Vendler. Se eu tiver cinco maçãs no cesto, eu poderei dizer ao meu interlocutor não só "peguei qualquer uma", como "peguei quaisquer duas", etc., até cinco. Mas nunca "quaisquer seis". Isto é, apesar de a possibilidade de ser escolhida cair sobre todas as maçãs, nunca todas serão escolhidas. A escolha também nāo exaure todas as possibilidades - se o meu interlocutor pegar as seis maçãs, jamais se poderá dizer que ele escolheu. 


\section{Conclusão}

Com base no que foi visto, podemos afirmar que a análise feita por Vendler (1967) para ANY manteve-se integralmente com relação a QUALQUER. Confirmou-se também a relação proposta entre os três itens, a qual dá a interpretação de verificação como básica, $\mathrm{e}$ as interpretaçōes de livre escolha (enriquecida com a noção de escolha arbitrária) e de incompletude como decorrentes da primeira. Observou-se ainda a força persuasiva de QUALQUER, a qual não decorre exclusivamente do uso, mas é inerente ao seu significado.

\section{RESUMO}

Este artigo tenta aplicar ao "quantificador" QUALQUER do portuguès a análise de Vendler (1967) para o inglés ANY. Argumenta-se que a interpretação de QUALQUER como verificação é a mais básica, e que as outras duas - a de livre escolha e de incompletude de escopo - decorrem da primeira. Além disso, a interpretação de livre escolha, no caso do português, deve incluir a de escolha aleatória.

Conclui-se que QUALQUER tem uma força persuasiva que não decorre do uso, mas que é inerente ao seu significado.

Palavras-chave: quantificação universah qualquer, pronomes indefinidos.

\section{RESÚMEN}

Este artículo intenta aplicar al "quantificador" QUALQUER (cualquiera) del portugués el análisis de Vendler (1967) para el inglés ANY. Se argumenta que la interpretación de QUALQUER como verificación es la más básica, y que las dos otras la de libre selección y de incompletud del escopo decurren de la primera. Además, la interpretación de libre elección, en el caso del portugués, debe incluir la de elección aleatoria.

Se concluye que QUALQUER tiene una fuerza persuasiva que no decurse de su uso, sino que es inherente a su significado. 


\section{REFERÊNCIAS BIBLIOGRÁFICAS}

KADMON N.; LANDMAN, F. Any. Linguistics and Philosophy. n. 16, 1993, p. 353-422. MATEUS, M.H.M. et al. Gramática da língua portuguesa. Lisboa : Caminho, 1989. PARTEE, B.; ter MEULEN, A. ; WALL, R.E. Mathematical methods in linguistics. Dordrecht : Kluwer, 1990.

VENDLER, Z. Each, Every, Any and Al. In: Linguistics in Philosophy. Ithaca, New York: Cornell University Press. 